\title{
A coprodução do zika no sertão nordestino brasileiro
}

\section{DINIZ, Débora}

Zika: do Sertâo nordestino à ameaça global

Rio de Janeiro: Civilização Brasileira, 2016. 192 p.

\section{I ${ }^{1}$ Fernanda Alzuguir I}

1 Instituto de Estudos em Saúde Coletiva, Universidade Federal do Rio de Janeiro. Rio de Janeiro-RJ, Brasil (fevecchi@iesc.ufrj.br). ORCID: 0000-0002-3162-5324.

Publicado no ano de 2016, em meio a um cenário de emergência sanitária pela epidemia do zika, o livro da antropóloga brasileira Débora Diniz, intitulado, Zika: do Sertão nordestino à ameaça global, é uma contribuição de grande relevância acadêmica e social.

Embora muitos trabalhos, sobretudo artigos, nacionais e internacionais, tenham sido publicados sobre o assunto desde o anúncio oficial da epidemia pelo Ministério da Saúde, em fins de 2015, o livro preenche importantes lacunas associadas às parcas publicações que analisam criticamente a problemática do zika a partir dos testemunhos da epidemia no sertão nordestino brasileiro.

Munida desse olhar, as lentes de análise sobre o zika são reajustadas e ampliadas para o contexto social mais amplo, que concorre para a coproduçáa ${ }^{1}$ do zika e suas correlaçôes. Das preocupaçóes em torno do mosquito vetor e do vírus zika, como componentes minúsculos isolados, em direção a uma complexa rede heterogênea que os compóem e os atravessam, formada por cientistas de bancada, médicos de beira de leito e pessoas comuns, homens e mulheres do sertáo nordestino, esse parece ser um dos grandes deslocamentos que o trabalho realiza.

E, como mostraremos, essa perspectiva mais ampliada produz rendimentos analíticos importantes acerca do impacto da desigualdade social e regional brasileira 
sobre a produção tecnocientífica do zika. A autora demonstra, assim, que o fato de ter sido o sertáo nordestino brasileiro o epicentro da epidemia teve consequências importantes na maneira como ocorreu a circulação e legitimação diferenciadas do conhecimento e tecnologia científicos sobre o zika entre círculos de especialistas, sobretudo no eixo Nordeste-Sul-Sudeste.

O livro é dividido em dois cortes temporais principais: em um primeiro momento, apresenta a chegada de um novo vírus no país; em um segundo, o foco recai sobre a construção da causalidade entre zika e a síndrome congênita do zika. ${ }^{2}$

Para tanto, ela empreende um estudo etnográfico a partir do contato diário entre equipes de saúde e mães nordestinas de filhos com microcefalia, visitas pelo interior do Nordeste e participação em seminários acadêmicos. Sua análise decorre da articulação de diversas fontes de informação, desde bibliografia científica nacional e internacional, até aquelas decorrentes da imersão etnográfica, como registros materiais e entrevistas com médicos, cientistas e mulheres nordestinas, em cinco estados: Alagoas, Bahia, Paraíba, Pernambuco, Rio Grande do Norte.

Essa produção polissêmica e vibrante tem como pano de fundo uma pergunta humilde para ciência, como a própria autora reconhece, mas não pouco relevante quando se trata do drama vivenciado pelas mães de filhos nascidos com microcefalia: o que significou a descoberta da transmissão vertical do vírus zika?

Para o enfrentamento dessa questáo, a autora se posiciona de antemão contra qualquer pretensão de neutralidade acerca do empreendimento científico e sobre sua história, que se realiza em meio a controvérsias marcadas por interesses, posicionamentos, projetos, instituiçóes, pessoas, corpos.

Sobre a história contada no livro, Diniz (2016) ressalta: "É possível que existam imprecisóes ou versôes a serem contestadas, pois as descobertas científicas [grifo da autora] nunca são solitárias: fazem parte de um amplo jogo de solução de quebracabeças em que vários jogadores concorrem simultaneamente. Houve intensa solidariedade entre pesquisadores e médicos brasileiros, mas também ressentimento e desavenças" (p. 8).

Considerando a complexidade desse quebra-cabeças, fica a importante ressalva na introdução do livro de que: "nem todos são colegas de uma mesma narrativa de descobrimento" (DINIZ, 2016, p. 9), de maneira que em alguns momentos a autora teve que escolher entre perspectivas e protagonistas. 
O capítulo introdutório, intitulado "A história contada", apresenta as condições teórico-metodológicas da investigação. O capítulo seguinte, "Deu Zika”, discute a chegada do vírus no Brasil. Ele é composto por três seções: "As origens", "A epidemia da alergia" e "A doença misteriosa".

Em "As origens", a autora empreende um breve resgate histórico sobre as origens do vírus zika - primeiramente, isolado em Uganda, na primeira metade do século $\mathrm{XX}$-, as epidemias subsequentes na primeira quinzena do século XXI (Gabão, Ilhas Yap, Polinésia Francesa e Brasil) e as hipóteses em disputa a respeito da chegada do zika ao Brasil. Em seguida, descreve as memórias de médicos nordestinos por ela entrevistados sobre as primeiras suspeitas a respeito de uma nova doença no sertão nordestino em fins de 2014 e 2015 até sua identificação como zika vírus. Regiōes do sertão nordestino como Mata Grande, Currais Novos (RN) e Camaçari (BA) são o palco onde se desenrolam as narrativas.

Assim, a primeira parte do livro desvela as interlocuçôes entre diferentes atores envolvidos nas investigaçóes sobre o zika, que, por suas particularidades, resistia às tentativas recorrentes de encaixá-lo como "dengue fraca", "alergia" ou até "doença misteriosa”. São eles: nordestinos no sertão - com suas queixas, coceiras, "febrículas", manchas na pele e amostras de sangue para pesquisa -, médicos de "beira de leito", infectologistas e virologistas da chamada ciência de bancada.

Essa primeira parte já é bastante elucidativa da maneira como as evidências científicas são produzidas e legitimadas no campo constituído pelos especialistas da ciência do zika. O olhar clínico dos médicos de beira de leito, articulado às queixas dos nordestinos infectados, não parece ter sido suficiente para o reconhecimento oficial do zika. Para isso, foi necessária a comprovação por parte de metodologias específicas em laboratórios reconhecidos do eixo Sul-Sudeste do país. Essa forma de circulação e tradução do conhecimento científico atravessa as duas partes do livro.

O segundo eixo temporal se volta à estabilização da relação entre a microcefalia e o zika, ${ }^{3}$ na segunda metade de 2015, na sequência cronológica à identificação do zika no Nordeste brasileiro no início do mesmo ano. Essa discussão aparece nos capítulos "A primeira geração de mulheres" e "A microcefalia". O primeiro capítulo é dividido nas seçôes: "A estrangeira" e "As nordestinas". Já o capítulo "A microcefalia" se divide nas seçôes: "A síndrome paralisante", "As neuropediatras de Recife" e "A médica do Cariri”. 
A partir das trajetórias de três mulheres que engravidaram no Brasil em um período ainda de reconhecimento da epidemia no país, a italiana Sofia Tezza e as nordestinas Géssica dos Santos e Maria da Conceição Matias, a antropóloga evidencia a experiência aflitiva de mulheres que se depararam com imagens alteradas de seus fetos no ultrassom em meio a um clima de incertezas científicas. Quando as imagens eram sinais sem diagnóstico para nomeá-los e traduzi-los, quando o agente patógeno era ainda um desconhecido sem nome.

As nordestinas são mulheres da região do Cariri na Paraíba. Apesar de viverem na mesma localidade, suas trajetórias se uniram a partir do encontro com a obstetra Adriana Melo, em um centro de referência em Campina Grande, uma figura importante na história da transmissão vertical do zika. Mesmo que isso não seja apresentado explicitamente, essa descrição mostra como o encontro afetivo na clínica, marcado pelo acolhimento e escuta interessada, foi um elemento central para a estabilização da correlação científica entre zika e microcefalia. Elemento esse que muitas vezes se dilui nas narrativas sobre a história oficial das "descobertas"“ científicas.

A seção "A síndrome paralisante" aborda a chegada aos hospitais, entre maio e outubro de 2015, de pessoas com paralisias em uma parte do corpo, antecedidas por sintomas semelhantes à "dengue fraca": coceiras, dores no corpo. Essa paralisia já tinha um nome na literatura médica: "Síndrome de Guillain-Barré". A novidade foi seu desencadeamento após os sintomas do zika. O médico clínico e epidemiologista pernambucano Carlos Brito é um dos atores que se destacam nessa seção, em sua suspeita de que uma nova epidemia explicava a síndrome.

O próximo capítulo apresenta as neuropediatras de Recife Ana e Vanessa Van Der Linden, mãe e filha, respectivamente, e suas indagaçôes a respeito do aumento de casos de bebês com microcefalia em suas clínicas. A partir do que seria considerado por Vanessa como seu "paciente zero", um gêmeo solitário ${ }^{5}$ recém-nascido atendido em agosto de 2015, esta passa a observar um padrão típico de tomografia caracterizado por calcificaçóes e comprometimentos neurológicos específicos, cuja emergência começa a ultrapassar as fronteiras da sua clínica particular para as maternidades públicas de Recife.

É interessante observar como as trajetórias de alguns entrevistados se entrecruzam na narrativa. Assim, mais do que atores isolados, o livro elucida que a ciência do zika se faz em uma rede dinâmica de encontros, desencontros e disputas entre especialistas, generalistas e a população. Um exemplo, entre vários que aparecem ao 
longo do livro, é a ligação telefônica de dra. Vanessa ao dr. Brito: “...estava convencido que dra. Vanessa lhe havia levado uma peça que se encaixava na potência do vírus zika - o adoecimento de uma multidão de pessoas nos meses iniciais de 2015, a síndrome paralisante pelo meio do ano, e agora os recém-nascidos afetados. $\mathrm{O}$ ciclo parecia se fechar: a epidemia de microcefalia parecia ser causada pelo adoecimento das mulheres pelo vírus zika durante a gravidez" (DINIZ, 2016, p. 95).

Ocapitulo finaliza com o anúncio, em novembro de 2015, da primeira comprovação de que o vírus zika atravessava a barreira placentária de grávidas, afetando, assim, os fetos. Esse anúncio inaugura, portanto, o capítulo sobre "A médica do Cariri". A primeira evidência científica veio justamente da disponibilidade de Géssica e Conceição em realizar a coleta do líquido amniótico, sobre quem, como vimos, Diniz dedica um capítulo prévio. A narrativa reconhece o protagonismo dessas mulheres na história da "descoberta" da transmissão vertical do zika. A amostra foi coletada por Adriana Melo em seu consultório particular, impulsionada por uma indagação que ela carregava durante os diálogos sobre o zika entre especialistas. Sobre isso, Diniz (2016) descreve: "Dra. Adriana acompanhava atentamente o que dr. Brito escrevia pelo WhatsApp ${ }^{6}$ e se inquietava com a hipótese de o vírus zika causar a microcefalia. Havia gente doente de virose aos montes em seu consultório de medicina fetal e nos ambulatórios da universidade em que fazia plantão. Dra. Adriana não entendia bem por que as descobertas do vírus zika havia saltado dos mosquitos para os recém-nascidos. Onde estavam as mulheres?" (p. 104).

Essa invisibilidade inicial em relação às mulheres é um tema que de fato demanda uma reflexão. O próprio encadeamento dos capítulos no livro é congruente com a cronologia das "descobertas" na história da epidemia: "dos mosquitos para as crianças" (2016, p. 90), como a pesquisadora destaca criticamente, para apenas depois chegar às gestantes. Aquela invisibilidade se traduz, por exemplo, no questionamento levantado pela autora sobre o paciente zero. Tratando-se de uma doença com transmissão vertical, esse paciente poderia ser tanto o recém-nascido afetado quanto a própria mãe adoecida pelo vírus, pondera. E complementa: “...se houve um paciente zero na epidemia do vírus no Brasil” (p. 90), possivelmente ele está entre as mães da primeira geração do zika.

O "paciente zero" é justamente o nome do capítulo que sucede o da médica do Cariri. Ele aborda a história do gêmeo recém-nascido de Custódia, no sertão pernambucano, atendido pela já referida neuropediatra de Recife e oficialmente 
identificado como o paciente zero da microcefalia. O porta-voz dessa história é Paulo, o pai do gêmeo.

Nesse breve capítulo, a autora retoma a reflexão sobre o paciente zero, a partir da enunciação do incômodo do pai em relação a essa identificação, tendo em vista a existência de crianças anônimas com microcefalia meses mais velhas do que o seu filho. Assim, a autora chama a atenção, mais uma vez, para a forma como a desigualdade socioeconômica afeta a trajetória do conhecimento sobre a microcefalia, quando diz: "Paulo sabe que o paciente zero não é exatamente o primeiro a ter sido afetado pelo vírus zika na gravidez, mas o primeiro paciente que fez a medicina despertar para a novidade. Porque a história não é contada pelo lado de quem sofre, mas por quem tem a palavra para contá-la” (DINIZ, 2016, p. 129).

Os capítulos finais: "O Serão nordestino" e "A ameaça global" se aproximam em seu caráter sintético e de encerramento. O primeiro sintetiza uma provocação que perpassa todo o livro: a de que, por trás de números e estatísticas dos informes epidemiológicos sobre os "casos" notificados de microcefalia, havia mulheres e recém-nascidos nordestinos cujos dramas e necessidades no enfrentamento da doença escapavam à mensuração estatística. Algumas mulheres acompanhadas pela autora durante sua pesquisa contavam com redes de apoio em grupos de WhatsApp, ${ }^{7}$ e se fortaleciam através da rede de solidariedade que dali se constituía. A depender da composição e recursos familiares, elas eram obrigadas a se desdobrar para conseguirem transporte para os centros de referência de apoio às suas crianças, como é o caso da moradora de um sítio em Monteiro, na Paraíba, que levava em torno de cinco horas para ir e voltar da estimulação precoce de seu filho nascido com microcefalia. Muitas mulheres, como ela, aguardavam o benefício assistencial para poderem cuidar dos filhos em tempo integral. Destaca, novamente, que as políticas de saúde pública para o enfrentamento do zika devem incluir a saúde reprodutiva das mulheres como alvo, para além do foco nos mosquitos.

O capítulo final, intitulado "A ameaça global", reflete sobre a magnitude do impacto da epidemia à saúde reprodutiva de mulheres em um âmbito global, questão publicamente reconhecida e anunciada pelo alerta da OMS, em fevereiro de 2016, sobre a síndrome congênita do zika como uma Emergência de Saúde Pública de Importância Internacional. Dois meses depois, a OMS declara o consenso científico a respeito da causalidade entre o zika e a microcefalia e, também, a Síndrome de Guillain-Barré. 
A transmissão sexual pelo zika começa a ser levantada nesse período. A recomendação da prática de abstinência sexual ou adiamento da gravidez pelo Ministro da Saúde atesta a importância de ampliar urgentemente a discussão centrada no enfrentamento do mosquito para a problemática da saúde reprodutiva das mulheres em idade fértil. Trata-se de pensá-la como uma questão de saúde pública da maior relevância - nacional e internacional -, que precisa ser mais seriamente debatida, considerando a discussão sobre a responsabilidade do Estado em garantir a saúde reprodutiva de mulheres.

Sensível às desigualdades que permeiam a sociedade brasileira em diferentes níveis, o relato da pesquisadora sobre a história da epidemia do zika traz à tona a avassaladora desigualdade regional do eixo Sul-Nordeste e sua repercussão na produção científica. Essa desigualdade se reflete em dois segmentos: tanto em relação aos nordestinos anônimos diretamente afetados, quanto em relação à participação dos chamados médicos de beira de leito no processo de produção tecnocientífica.

Assim, do ponto de vista da relação entre a comunidade científica e a população leiga, os nordestinos, e sobretudo nordestinas, anônimos, tornam-se, na narrativa, protagonistas na história sobre o zika. Já do ponto de vista do modus operandi do processo de produção e divulgação tecnocientífica entre a rede de especialistas envolvidos nas investigaçôes sobre o zika, a autora desvela como a história oficial é bastante seletiva em relação aos porta-vozes legitimados do "descobrimento" deste novo fato científico: ${ }^{8}$ foram sobretudo cientistas de laboratório vinculados a uma instituição de renome do eixo Sul-Sudeste que detiveram a palavra final na comprovação das evidências científicas - através de metodologias específicas - e na divulgação oficial da novidade. Desse modo, na base menos prestigiada dessa estratificação social estavam as médicas nordestinas de beira de leito e, no topo, os cientistas de bancada da região Sul-Sudeste. Assim, não se trata de ignorar a existência de relaçôes de solidariedade entre especialistas de diferentes regiôes, mas de evidenciar que a ciência do zika foi também afetada pelo regime desigual regional de distribuição do reconhecimento científico, marcado por "disputas típicas da ciência sobre quem publicaria os estudos de descobrimento ou anunciaria os grandes feitos" (DINIZ, 2016, p. 139). A urgência em publicizar as "descobertas" se refletia visivelmente na prática recorrente dos médicos nordestinos de divulgação dos resultados à imprensa antes de serem publicados em artigos científicos. 
Uma das grandes contribuiçôes da narrativa é justamente a desestabilização da lógica hegemônica de organização da comunidade científica através de uma espécie de inversão do modo hierárquico de compreensão da divulgação e produção tecnocientífica do zika. Desse modo, a autora elucida a participação de nordestinos anônimos afetados por uma doença sem nome, assim como das médicas e médicos nordestinos de beira de leito que se depararam diretamente com uma nova manifestação clínica no sertão e tiveram papel importante na mobilização do trânsito de recursos e informaçóes para os grandes centros de pesquisa.

A história contada sobre o zika abre um campo extremamente fértil para o aprofundamento de uma reflexão crítica sobre o empreendimento científico a partir do aporte dos estudos sociais da ciência. A narrativa testemunha a impossibilidade de pensar a produção tecnocientífica desgarrada do cotidiano da vida social (ROHDEN, 2012).

Fleck (2010) traz contribuiçôes valiosas em direção à referida desestabilização, ao afirmar que a ciência, longe de ser a obra de indivíduos ou grupos isolados, é uma atividade coletiva complexa e dependente de trocas e diálogos dentro e entre diferentes coletivos de pensamento. Ele define um coletivo de pensamento como uma comunidade de pessoas que intercambiam ideias entre si.

Segundo o autor, em torno de um coletivo de pensamento formam-se pequenos círculos esotéricos e círculos exotéricos maiores. O primeiro se refere ao terreno dos experts, especialistas ou generalistas, diretamente envolvidos com o processo de produção tecnocientífica. Entre as formas de comunicação privilegiada do primeiro círculo estão os manuais e periódicos técnico-científicos. Já o círculo exotérico referese ao campo dos "leigos mais ou menos instruídos", sustentados pela divulgação feita pela chamada ciência popular.

O que nos interessa mais particularmente na apresentação dessas concepçóes é destacar que a coprodução do zika no contexto do sertão nordestino brasileiro resultou da comunicação entre diferentes saberes, populares e especializados. Essa comunicação pode ser bem ilustrada pela relação entre especialistas e imprensa, a exemplo do costume dos médicos nordestinos de divulgação dos achados sobre o zika à imprensa antes da sua publicação nos círculos acadêmicos mais fechados, através de artigos científicos. A compreensão desse tipo de publicização dos achados do zika - dos círculos esotéricos aos exotéricos -, em meio a um clima de intenso debate científico entre especialistas, merece de fato uma análise de maior fôlego que não caberia no 
escopo dessa resenha. No entanto, algumas condiçóes para esse fenômeno podem ser aventadas, entre as quais, a situaçáo de urgência sanitária no contexto da epidemia e a pressão pública para a divulgação à população. Ao mesmo tempo, o artigo de Cassidy (2006) fornece pistas sobre a concorrência de explicaçóes menos evidentes. Entre elas, a utilização de veículos de divulgação popular como uma maneira de se desvencilhar dos constrangimentos da comunidade científica, o que faz sentido, quando consideramos o regime de distribuição desigual da pesquisa científica sobre o zika.

A discussão sobre gênero e ciência também é outro campo profícuo que pede um aprofundamento analítico, levando em conta a possibilidade aberta pela narrativa para consideraçóes críticas sobre o lugar concedido ou não às mulheres nordestinas especialistas e as gestantes da primeira e segunda geração do zika - na ciência oficial do zika, e sua relação com a saúde reprodutiva feminina.

A autora nos deixa, portanto, um registro valioso sobre a história de uma nova doença no sertão nordestino, evidenciando como ela se fez a partir da atuação conjunta de saberes leigos e especializados. Se, segundo a autora, a ciência do zika não escapou de um estilo de pensamento característico da chamada ciência normal (KUHN, 1998), sua narrativa tem o mérito de problematizar sua lógica de construção, ao mostrar que o fato de ter sido o sertão nordestino o epicentro da epidemia impactou diretamente o modo de divulgação e produção tecnocientíficas em torno do zika. Assim, ela nos convida a desestabilizar as fronteiras entre a ciência do zika e o cotidiano do sertão nordestino.

\section{Referências}

CASSIDY, A. Evolutionary psychology as public science and boundary work. Public Understand. Sci., 15, 2006, p. 175-205, 2006.

FLECK, L. Gênese e desenvolvimento de um fato cientificocientífico. Belo Horizonte: Fabrefactum, 2010.

JASANOFF, S. The idiom of co-production. In: . (Ed.). States of knowledge: the coproduction of science and social order. London and New York: Routledge, 2004.

KUHN, T. A estrutura das revoluçôes científicas. São Paulo: Saraiva, 1998.

ROHDEN, F. Notas para uma antropologia a partir da produçâo do conhecimento, os usos das ciências, intervençôes e articulaçôes heterogêneas. In: FONSECA, C.; ROHDEN, F.; MACHADO, P. S. (Orgs.). Ciências na vida: antropologia da ciência em perspectiva. São Paulo: Terceiro Nome, 2012. 


\section{Notas}

${ }^{1}$ Embora Diniz (2016) não utilize a noção de coprodução, levantamos aqui a potência analítica dessa noção na perspectiva dos estudos sociais da ciência. Segundo Jasanoff (2004), a coprodução se refere menos a uma teoria e mais a um idioma, uma forma de compreensão dos fenômenos complexos, como é o caso do conhecimento científico e da tecnologia, que concebe tanto a ordem natural quanto a ordem social como produçốes interconectadas. Segundo essa noção, conhecimento científico e tecnologia incorporam e são, ao mesmo tempo, incorporados por práticas sociais, identidades, discursos, instituiçóes, normas, instrumentos, convençóes. Tal idioma é uma crítica à ideologia realista que tende a separar insistentemente os domínios da natureza, fatos, objetividade, razão dos domínios da cultura, valores, subjetividade, emoção.

${ }^{2}$ Em alguns momentos, o termo microcefalia é intercambiado no livro pela denominaçáo síndrome congênita pelo zika. Essa diferença terminológica não passa, no entanto, despercebida por Diniz (2016, p. 153), que, já em sua primeira nota de rodapé, afirma: "O mais preciso seria descrever como a síndrome congênita do zika”, um conjunto de sinais e sintomas dos quais a microcefalia é apenas uma das características. Apesar dessa ressalva, declara que a OMS e as mulheres da pesquisa ainda usam o termo microcefalia.

${ }^{3}$ Ver nota de rodapé no 2 .

${ }^{4}$ Grifamos o termo para ressaltar a crítica à ideia de descoberta científica espontânea por um pesquisador. Sobre isso, ver as consideraçôes de Fleck (2010, p. 133) sobre o "conto de fadas ingênuo" do pesquisador que reconta as suas observaçóes a partir da crença no mito do conquistador segundo a fórmula "Vim, vi, venci".

${ }^{5} \mathrm{O}$ outro irmão gêmeo não foi afetado pelo vírus.

${ }^{6}$ Grupo de WhatsApp "Chigv: a missão", que se mostrou uma ferramenta de diálogo entre diferentes médicos do Nordeste sobre o zika.

${ }^{7}$ A autora participou de dois grupos de WhatsApp de mães de crianças com microcefalia, entre eles, o grupo "Mães do HMPI", cujos filhos são acompanhados no Hospital Pedro I, em Campina Grande.

${ }^{8}$ Ver Fleck (2010). 